\title{
Alienación territorial a través del patrimonio mundial: análisis de la Lista del Patrimonio Mundial de América Latina y el Caribe desde la perspectiva de la geopolítica crítica
}

\author{
Rocío Arroyo BeLMONTE*
}

\section{RESUMEN}

La acumulación de un patrimonio cultural, como una selección de bienes o manifestaciones sociales transmitida sucesivamente para generaciones futuras, se origina en los proyectos nacionalistas de los estados durante la modernidad, principalmente en un contexto europeo. Más adelante, con las funestas consecuencias de las guerras mundiales, este modelo se universaliza para tratar de conformar un patrimonio común a toda la humanidad. A partir de entonces, instituciones internacionales como la Organización de las Naciones Unidas para la Educación, la Ciencia y la Cultura (UNESCO) han buscado dirigir los esfuerzos hacia este fin, de manera central a través de la Convención del Patrimonio Mundial de 1972. Sin embargo, la participación en estos mecanismos está fuertemente politizada y centrada en las capacidades e intereses nacionales de los países, por lo que prevalece una supeditación a estrategias geopolíticas alrededor de la figura estatal. Siguiendo este supuesto, el presente artículo busca analizar críticamente las propiedades del patrimonio mundial enlistadas según lo marcado por la convención de 1972 en el caso particular de América Latina y el Caribe (ALyC), esto desde la perspectiva teórica de la geopolítica crítica.

El artículo se compone de dos secciones: en la primera se traza el origen histórico y estatista del patrimonio mundial, abordando los aportes de la teoría crítica del patrimonio y de la geopolítica crítica para estudiar este fenómeno; en la segunda se aborda particularmente la región de ALyC, revisando metodológicamente los procesos de inscripción, tipología, distribución y justificaciones del valor universal excepcional de las propiedades del patrimonio mundial en esta zona del planeta. Considerando que en las luchas interestatales influyen narrativas, imágenes y metáforas para imponer representaciones simbólicas dominantes del espacio, se propone que el patrimonio mundial es una metanarrativa que puede favorecer la alienación de territorios. Esto porque formas sociales de significar, usar y producir un territorio localmente son absorbidas por una memoria histórica nacional, en un primer momento, $y$ alienadas más adelante dentro de un ideal patrimonial de apariencia universal, pero naturaleza selectiva. En esta alienación la imposición de versiones oficiales de la historia, valoraciones con categorías exógenas y alegorías son impuestas institucionalmente, lo cual puede reproducir una jerarquización espacial con centros y periferias. Se concluye que en el patrimonio mundial que se ubica en la región latinoamericana, pese a un proceso tardío de adhesión por desconfianza inicial a la convención de 1972, prevalece una subrepresentación frente a otras regiones del mundo, permean deficiencias estructurales entre países que impiden participar igualitariamente en los órganos decisorios y se presenta una forzada adopción de categorías patrimoniales que propicia una reproducción acrítica de narrativas históricas bajo cánones valorativos europeos.

El resultado final es que muchos de estos territorios sufren un proceso de alienación donde se separa en forma artificial la relación entre ser humano y naturaleza, se menosprecia a las culturas originarias y se sobrevalora el legado del pasado colonial europeo, así como del cristianismo católico, lo cual repite una tradición extractivista y periférica de la región, absorbiendo o negando otras relaciones territoriales del pasado y presente.

\section{Palabras clave}

América Latina y el Caribe; patrimonio mundial; patrimonio cultural; geopolítica; territorio; UNESCO.

Recibido:

|5.03.202|

Aceptado:

22.07.2021

\section{TITLE}

Territorial alienation through World Heritage: analysis of the World Heritage List of Latin America and the Caribbean from a critical geopolitical approach

\section{EXTENDED Abstract}

Cultural heritage, understood as the selection of sites or cultural manifestations transmitted for future generations, is rooted in the nationalist projects of states during European modernity. After the terrible consequences of the world wars this

DOI:

https://doi.org// 0.15366/relacionesinternacionales2021.48.007

Formato de citación recomendado:

ARROYO BELMONTE, Rocío (202I). "Alienación territorial a través del patrimonio mundial: análisis de la Lista del Patrimonio Mundial de América Latina y el Caribe desde la perspectiva de la geopolítica crítica”, Relaciones Internacionales, $\mathrm{n}^{\circ} 48, \mathrm{pp} .123-141$. 
conservation model was universalized searching to preserve the heritage of mankind and supporting, at the same time, the construction of a liberal international order. Since then, international organizations have sought to direct efforts towards this goal. In 1972 the Convention Concerning the Protection of the World Cultural and Natural Heritage emerged as a result of discussions at the United Nations Educational, Scientific and Cultural Organization (UNESCO). This convention was concerned about the deterioration or disappearance of cultural or natural heritage, something viewed as harmful and an impoverishment of the heritage of all the nations of the world. This is why the agreement summoned the states to participate in the protection of world heritage of outstanding universal value, by cultivating collective cooperation and assistance.A list of monuments and sites that form part of world heritage was established, in terms of aesthetic, historical, artistic or scientific criteria. However, over time, in the selection process of world heritage sites disputes and power asymmetries have arisen between countries around the control of space.

This problem can be analyzed through Critical Heritage and Critical Geopolitics approaches, spanning the historical changes and current critical debates about heritage, as well as the political processes of narratives, metaphors and social image constructions around territory. We propose that nominating a territory as a world heritage site generates its alienation. That is, states absorb local territories (understood as a social construct) into dominant national narratives and images, subsequently, countries consolidate their appropriation by enlisting their nationalized territories within the meta-narrative of world heritage. In this process, countries must participate in a highly politicized and structurally unequal international negotiation that reproduces spatial hierarchies. Ultimately, these local territories and practices suffer a process of assimilation into the allegory of world heritage. With this in mind, the aim of this study is to analyze the territorial alienation of properties inscribed on the World Heritage List by Latin American and Caribbean (LAC) countries as a case study. This alienation occurs because, given the conditions of UNESCO, the countries of the region must adopt an artificial set of categories, typologies and narratives, absorbing or denying other territorial practices. This paper is divided in two sections. The first section gives a brief overview of world heritage origins centered on national projects within a specific European context, and explains Critical Heritage and Critical Geopolitics approaches.

A discussion of the evolution of world heritage categories and symbolic aspects of power is reviewed, highlighting the imposition of historical narratives in official documents, the reproduction of aesthetic codes and the construction of imaginaries around the past of territories. The second section analyses the particular case of theWorld Heritage List in Latin America and the Caribbean. In order to study territorial alienations, methodologically we review countries ratifications of the 1972 convention, the total number of sites, obstacles in international negotiations, narratives, as well as historical events commemorated by the world heritage officially recognized in this part of the planet. The inscription of a site on the World Heritage List requires a nomination file.We used the UNESCO's files to detect these historical narratives and discourses. Some conclusions are drawn, our findings would seem to show that world heritage sites in Latina America and the Caribbean are underrepresented compared to Europe and North America. In addition, these sites are geographically concentrated in South America, with the Caribbean as the least favored sub-region. At the beginning, countries were reluctant to ratify the 1972 convention due to the prevailing ColdWar context, but gradually all countries in the region accepted the commitment. States like Mexico top the List ofWorld Heritage sites, but others have no sites recognized; differences in the number of sites registered by the countries do not only stem from their geographical attributes and their historical past, but also because of the political, technical and economic potential to participate in diplomatic negotiations at UNESCO.

Arguments for inscribing a site as world heritage in this region highlights the relevance of natural and exotic places. This looks like a continuity of dominant imperialist narratives during the conquest and colonization of the continent America. The separation between natural and cultural world heritage is an artificial division adopted, but contrary to some local traditions in the region.The arrival of Europeans to Latin America has been established as a time marker used for example to talk about "pre-Columbian" cultures. In any case, few sites commemorate pre-Columbian civilizations, with the exception of the Mayas and the Incas, which contrasts with the cultural diversity and traditional groups that are not part of these dominant versions of the past. It may be assumed that in historical commemorations of world heritage sites in this region, the colonial past is notoriously overvalued and magnified; that is, it is presented as a favorable stage indicating a kind of cultural sophistication for indigenous people. Amazingly, territories essential to fulfilling their goal of extracting natural resources for the European settlers are now uncritically recognized as world heritage (for example mining centers, plantations, seaports or strategic villages). Similarly, cultural sites of Roman Catholic Christianity are evoked as a favorable contribution for the historical regional memory, but denying impositions around the conflictive and complex process of evangelization; in the same way other religions and beliefs are omitted.There are many colonial sites enlisted as world heritage but very few referring to the modern history of the region, significantly reformist narratives are absent: independence movements, abolition of slavery or contemporary indigenous and black population claims are not raised.

In summary, these results suggest that, from a critical perspective, the world heritage sites in LatinaAmerica and the Caribbean allow dominant relations to continue through values of European origin, selective historical narratives and illusory images as a colonized region.As long as other relevant regional historical events or social actors are ignored, the regional past and cultural heritage will be incomplete. The region reaffirms its peripheral and subordinated position in the international system through historical narratives acritically adopted. Latin American and Caribbean territories are more than exotic landscapes and places of colonial splendor for tourism. Analyzing world heritage from a critical perspective is a way to re-center the territory as a key axis in this dynamic and to recognize other memories and spatial relations.

\section{KEYWORDS}

Latin America and the Caribbean; world heritage; cultural heritage; geopolitics; territory; UNESCO. 


\section{ntroducción}

Conservar testimonios materiales o inmateriales del pasado para que sean heredados por generaciones futuras dentro de un patrimonio cultural ha sido un largo proceso histórico. Un gran impulso sería la intención de fortalecer los apegos nacionalistas hacia un territorio en la conformación de los estados durante la modernidad europea. Formar un carácter nacional, seleccionar monumentos para demostrar la magnificencia del pasado colectivo y acumular o exhibir bienes culturales como una forma de prestigio estarían motivados por un proyecto de nación. A lo largo del siglo XIX, este modelo iría exportándose de Europa occidental hacia otras regiones del mundo, acompañando los avances imperialistas de algunos países.

Trascender los patrimonios nacionales para formar un acervo común para todos los grupos culturalmente diversos del planeta enfrentaría algunas reticencias iniciales. Con la excepción de algunos filósofos humanistas, en el siglo XIX e inicios del XX dominaban ideologías raciales, proyectos colonialistas y rivalidades entre países. No obstante, las dos guerras mundiales y sus efectos destructivos desde 19/4 hasta 1945 motivarían la intención de seleccionar, salvaguardar y conservar monumentos, conjuntos y lugares representativos de las civilizaciones del mundo.Así nacería la Convención sobre la Protección del Patrimonio Mundial Cultural y Natural de 1972, como un instrumento interestatal emanado de la UNESCO para "construir la paz en la mente de los hombres y de las mujeres" (UNESCO, 2019). A pesar de las buenas intenciones, la realidad es que este objetivo estaría relacionado con una estrategia de seguridad para establecer un nuevo orden internacional de posguerra.

Bajo este encuadre estatal, los trabajos por inventariar propiedades del patrimonio mundial han permanecido supeditados a estrategias y capacidades de los países participando en los instrumentos internacionales, así como replicando asimetrías estructurales en el sistema global. La región occidental europea, al ser la cuna de inspiración de este movimiento de conservación patrimonial, había venido liderando las acciones de protección del patrimonio mundial expandiendo colateralmente sus cánones de valores, políticas de restauración y versiones dominantes de la historia.

Esto ha generado diferentes cuestionamientos, teóricamente el análisis crítico del patrimonio mundial se ha incrementado en los últimos años (Byrne, 199I; Graham et al., 2000; Harvey, 200 I; Lowenthal, 2005; Smith, 2006; Di Giovine, 2009; Adell, 20I 5; Harrison, 20 I2; Meskell et al., 20 I5; Wiktor-Mach, 2019). En estos estudios se critica el dominio de Occidente, la politización en la toma de decisiones en el Comité del Patrimonio Mundial, asimetrías, discursos institucionalmente dominantes $y$, en general, la negación de otras formas de significar y vivir el patrimonio cultural. A esto se suman visiones de la llamada geopolítica crítica que otorgan especial relevancia a los procesos culturales como procesos políticos en la lucha por el espacio (Ó Tuathail, 1996 y 1998 ; Agnew, 1993; Ó Tuathail y Dalby, 2002). Ambas visiones teóricas críticas podrían complementarse para el estudio del patrimonio tomando como eje de análisis el papel de metáforas, narrativas e imágenes alrededor de los territorios dentro de la construcción desigual del patrimonio mundial.

Es así como el presente trabajo propone analizar críticamente las propiedades hasta ahora inscritas en la Lista del Patrimonio Mundial por parte de los países de América Latina y el Caribe (ALyC), considerando que aquí se suscita una alienación territorial a través de la metanarrativa 
del patrimonio de la humanidad. Esta alienación se da porque, dadas las condiciones de inscripción de la UNESCO, los países de la región deben adoptar, de manera forzada y artificial, un conjunto de categorías, tipologías y argumentos valorativos ajenos a las prácticas territoriales locales. Esta situación fortalece la reproducción de jerarquías espaciales donde los aportes de la región se presentan como periféricos, negando o absorbiendo otras formas locales de relacionarse con el territorio y con el pasado.

\section{Patrimonio mundial como proceso geopolítico: debates teóricos}

Para hacer una revisión del marco teórico en el estudio crítico del patrimonio mundial, se debe partir del surgimiento de la idea de la conservación de bienes del patrimonio cultural. La intención de conformar un patrimonio cultural se ubica en la modernidad a finales del siglo XIX y principios del siglo $X X$ en Europa. Esta situación devino de una creciente intención por conservar antigüedades frente a las imparables transformaciones producidas por la revolución industrial, las revueltas liberales de 1848 y las guerras napoleónicas (Choay, I 992; Lowenthal, 2005; Riegel, 2008). El patrimonio surgió en forma de evocaciones nostálgicas sobre el pasado, buscando dar sentido al convulso presente de la época, como una muestra de desconfianza en el futuro, la sensación de pérdida y también como un síntoma de malestar (Lowenthal, 1998).

Al mismo tiempo se fortaleció el nacionalismo en consonancia con la paulatina formación de los estados, los cuales fomentaron el apego a monumentos antiguos como símbolos de identidad colectiva y como testimonios materiales de un pasado en común (Choay, 1992). Los estados más fuertes, que disputaban el dominio regional europeo en ese momento, fueron recreando sus propios modelos y prácticas de conservación de monumentos históricos (particularmente Reino Unido, Francia,Alemania e Italia). Desde finales del siglo XIX y a lo largo del siglo XX, estas prácticas de conservación del patrimonio serían exportadas a otras regiones del mundo intrincadas con la expansión imperial europea. La acumulación de bienes culturales exóticos extraídos de los territorios conquistados por parte de las metrópolis era un motivo de prestigio y fuerza.

Al prevalecer un contexto de rivalidades nacionalistas con visiones subyugantes hacia otros territorios en el mundo, pensar en un patrimonio común para toda la humanidad donde los independentistas latinoamericanos, los africanos recién colonizados o los rivales comerciales asiáticos conjuntaran sus acervos materiales en una memoria colectiva global, resultaba simplemente irrisorio. Sin embargo, dicha situación cambiaría abismalmente con las guerras mundiales desde 1914 y hasta 1945. Siguiendo a Iriye (1997) varios procesos facilitaron un giro internacional hacia la protección de un patrimonio mundial: la preocupación ante el daño o destrucción de varios monumentos históricos durante las conflagraciones; el fortalecimiento de un ambiente de cooperación que abogaba por la paz a través de la educación y la cultura; los avances científicos en las técnicas de conservación y restauración de bienes culturales; así como el afianzamiento de precedentes legales internacionales en materia de protección y conservación del patrimonio.

Las entidades estatales fueron quienes lideraron los esfuerzos para construir un régimen de protección del patrimonio de la humanidad. Este irenismo cultural implicó también una estrategia 
de seguridad para acompañar la reconstrucción del orden mundial de posguerra, regulado a través de normas y juicios de expertos con el patrimonio como vehículo (Harvey, 200 I; Smith, 2006; Di Giovine, 2017).

En la compleja negociación para definir el patrimonio de la humanidad se fusionaron varias corrientes de pensamiento y prácticas de conservación, por lo que establecer una definición relativamente consensuada nunca fue, ni será, una labor fácil. Una institución internacional clave para conducir estos esfuerzos fue la UNESCO ya que, desde su creación en 1945 y hasta la actualidad, se ha encargado de definir, regular y gestionar el patrimonio mundial a través de diversas recomendaciones, convenciones y programas guiados por los expertos técnicos, convirtiéndose en una de las “instituciones autorizadoras del patrimonio" (Smith, 2006, p. 87).

Particularmente, uno de los acuerdos centrales en la materia establecido por este organismo internacional ha sido la Convención sobre la Protección del Patrimonio Mundial, Cultural y Natural de 1972, la cual se encarga de seleccionar monumentos, conjuntos y lugares por su valor excepcional para la memoria de la humanidad. La categorización original del patrimonio mundial según este acuerdo tuvo un notable influjo de la Europa occidental (Jokilehto, 2005). En esta convención el patrimonio mundial originalmente tendría dos grandes rubros: el cultural y el natural. El primero incluiría a "monumentos, conjuntos y lugares" con un valor excepcional desde el punto de vista histórico, artístico, científico, estético, etnológico o antropológico.Y, por su parte, el patrimonio mundial natural estaría conformado por los "monumentos naturales, formaciones y zonas" con un valor universal excepcional desde el punto de vista científico, geológico, de la conservación ecológica o la belleza natural (UNESCO, 1972).

La distinción de monumento referenciaba a grandes inmuebles aislados, sin considerar su entorno circundante. El término de conjunto tendría un sentido más abarcador, se adoptaría como una herencia desde la arqueología y la arquitectura. Mientras que la clasificación de lugar daría mayor reconocimiento a la conexión entre ser humano y naturaleza, retomado desde la geografía humana. La separación de zonas naturales de las culturales fue una concepción heredada del movimiento romancista de finales del siglo XIX, con la intención de conservar zonas prístinas fuera del alcance de la acción del ser humano (Lowenthal, 2005).

En la década de los ochenta comenzaron entonces a generarse críticas sobre la visión marcadamente occidental en la definición del patrimonio mundial. Los estudios críticos del patrimonio emergieron en este contexto asociados con cambios internacionales como el auge del turismo cultural, el paulatino fin de la Guerra Fría y las tendencias revisionistas decoloniales sobre cómo el patrimonio cultural debía ser significado, reproducido y experimentado en diferentes partes del mundo, incluyendo a grupos indígenas y comunidades marginadas (Harvey, 200I; Di Giovine, 2009; Silverman, 20I I; Meskell et al., 2015a).

A lo largo de la década de los noventa, los grandes retos impuestos por la globalización, el auge de las industrias culturales y las revoluciones tecnológicas fortalecieron el movimiento crítico alrededor del patrimonio mundial. Algunos países disidentes denunciaron la subjetividad en la interpretación del valor excepcional y la monumentalidad privilegiada por la convención de 1972, aclamando la inclusión de manifestaciones intangibles e inmateriales de la diversidad 
cultural (UNESCO, 1997). Con esta presión comenzaron a ser reconocidas otras nominaciones como centros históricos, arquitectura contemporánea, patrimonio vernáculo, paisajes históricos urbanos, bienes industriales, rutas culturales, patrimonio fósil, entre otros.

Para el inicio del siglo XXI, los estudios del patrimonio afrontan nuevos retos que Silverman (20II) ha sintetizado acertadamente: producción, comercialización y consumo del patrimonio; propiedad extranjera de antigüedades ilegales traficadas desde los países de origen; divulgación pública del patrimonio de grupos que sufrieron apropiación de sus derechos; el concepto de valor que incluye preguntas sobre las acciones de la UNESCO en la labor del patrimonio cultural; ubicación y despliegues nacionales del patrimonio cultural en un mundo global; patrimonio y política; patrimonio inmaterial; e intersecciones del patrimonio con la cultura y derechos humanos.

En este contexto de clara deconstrucción del patrimonio cultural surgen nuevos acuerdos de la UNESCO tratando de cubrir estas nuevas demandas, como la Convención sobre la Protección del Patrimonio Cultural Subacuático de 200I; la Declaración de Budapest en 2002 promoviendo las cinco C (credibilidad, conservación, capacidades, comunicación y comunidad); la Convención para la Salvaguardia del Patrimonio Cultural Inmaterial de 2003 y la Convención sobre la Protección y Promoción de la Diversidad de Expresiones Culturales de 2005.

A pesar de esta aparente inclusión, inmaterialidad y desterritorialización del patrimonio de la humanidad en las últimas décadas, en la práctica internacional sigue predominando el reconocimiento de un acervo mundial asociado con los estados. Por ejemplo, la convención encargada de la salvaguarda del patrimonio mundial intangible en su comité realizado en Bali en $201 \mathrm{I}$, determinó que en el futuro no se inscribiría una práctica que no se ejerza exclusivamente en el país que la proponga; incluso un país no puede nominar una expresión asociada a otro, aunque éste no tenga inconveniente en así hacerlo (Adell et al., 20I5).

Contrario a su ideario enmarcado en la cooperación, la convención nodal de 1972 sigue teniendo vigencia hasta nuestros días y se ha implementado dentro de jerárquicas relaciones de poder. La inscripción de una propiedad en la Lista del Patrimonio Mundial es un proceso burocrático mediado por negociaciones ocultas, intercambio de votos, formación de alianzas y el ejercicio diplomático más que técnico y científico (Harvey, 200 I; Harrison, 20 I2; Adell et al., 2015; Di Giovine, 2017; Wiktor-Mach, 2019). Los países suelen tomar sus decisiones como una estrategia para reforzar sus intereses nacionales, utilizando al patrimonio mundial como un peón, prevaleciendo negociaciones de poder entre las naciones con alianzas geopolíticas basadas en geografía, religión, acuerdos comerciales o alianzas políticas (Meskell et al., 20I5b).

En recientes discusiones sobre este tema comienza incluso a desmoronarse el predominio occidental que tanto han reclamado los estudios críticos patrimoniales. La fuerza tomada por el grupo regional de Asia y el Pacífico, particularmente de China, desafían el liderazgo tradicional de Europa y Norte América (Meskell, et al., 20I5b); estamos en los albores de la "era asiática en el régimen del patrimonio mundial” (Wiktor-Mach, 2019, p. 1605).

Un régimen del patrimonio mundial que fue creado por y para los estados puede generar cierto grado de adaptabilidad, pero ontológicamente conserva su estatismo. Aunque se han dado 
variaciones en las categorías del patrimonio mundial, estas siguen estando encuadradas en los límites políticos de un estado internacionalmente reconocido. Tal condición promueve la lucha entre países por imponer su visión histórica del mundo y alienar territorios. Es por este motivo que el proceso podría ser abordado teóricamente desde lo aportes de la geopolítica crítica.

El territorio no es sólo físico, sino simbólico y socialmente construido, así lo han venido evidenciando los grandes analistas de este tema desde diferentes corrientes de pensamiento (Hubbard y Kitchin, 20 I I). Dentro de estas tendencias se encuentra la llamada geopolítica crítica - nueva geopolítica que reprocha el determinismo geográfico, racionalismo y pragmatismo como estrategia exclusiva en las rivalidades por el espacio. En esta vertiente analítica ya no se aspira únicamente a generar operaciones militares defensivas y se insta a repensar el ejercicio del poder. Con el influjo de corrientes posmodernas de las ciencias sociales, una de las grandes preocupaciones es justamente integrar los aspectos simbólicos de la realidad social como un eje axial.

Uno de los grandes impulsores de la geopolítica crítica, Ó Tuathail (1996), considera que el centro analítico debe estar ahora en las etiquetas, narrativas, imágenes y metáforas espaciales que se tienen del mundo. Bajo esta lógica, cobran relevancia las prácticas sociales a través de las cuales se generan estos dispositivos para explicar la realidad, donde entidades estatales implementan políticas para crear (e imponer) narraciones históricas nacionalistas que coadyuvan a legitimar gobiernos, justificar acciones de política exterior, arraigar jerarquías sociales o, inclusive, negar o absorber otros territorios (Ó Tuathail y Dalby, 2002). De esta manera todos los estados, como instituciones territoriales reconocidas dentro de un sistema internacional, tienen una forma de conceptualizar a su propio país, su identidad, así como su posición o rol internacional (Ó Tuathail, 1996).

La declaratoria de un territorio (o manifestación cultural asociada a este) como patrimonio mundial puede favorecer su alienación. Inicialmente, los estados absorben territorios locales (entendidos como una construcción social) dentro de narrativas e imágenes nacionales dominantes. Posteriormente, ese país consolida su apropiación al enlistar sus territorios nacionalizados dentro de la metanarrativa del patrimonio mundial que es de apariencia universal, pero naturaleza selectiva. En dicho proceso los países deben además involucrarse en una negociación internacional altamente politizada y estructuralmente desigual que reproduce jerarquías espaciales entre estados. Al final de cuentas, estos territorios y prácticas locales sufren un proceso de alienación donde, con la alegoría del patrimonio de la humanidad, se diluye una real apropiación al ser renombrados con categorías exógenas y descolocados de su propia historia. Estos territorios en algunas ocasiones se adaptarán, pero también pueden suscitarse resistencias, enajenación u ocultamiento de otras prácticas territoriales (presentes y pasadas).

Esta situación puede crear discursos narrativos e imágenes en disputa, un despliegue de rivalidad entre representaciones dominantes del espacio (Agnew, 1993). Las narraciones históricas respecto a un territorio son piezas claves, pues no son solo el cúmulo inagotable de episodios pasados, sino la selección de ciertos eventos del ayer que se sacralizan y consagran espacialmente de acuerdo al contexto presente. 
El revolucionario historiador Pierre Nora (1984) denomina acertadamente a estos espacios como "lugares de memoria", sitios que sacralizan eventos históricos que una colectividad selecciona, segrega, erige, establece, construye, decreta o mantiene en forma artificial o voluntaria. Los lugares de memoria sacralizan recuerdos con el fin de generar pertenencias, aunque, debido a su misma naturaleza, también pueden deformarse, transformarse, moldearse o petrificarse. Estos marcadores territoriales resultan de fuerzas y rivalidades de poder, antiguas o recientes, articulándose en diferentes escalas espaciales. Además, estos lugares pueden formar dispositivos que ayudan a reproducir determinadas lógicas de jerarquización de las diferencias espaciales dentro de la "geopolítica de la memoria" (Piazzini Suárez y Montoya Arango, 2008).

Estos efectos han sido también abordados por los geopolíticos críticos con un matiz decolonial desde la región latinoamericana. Por ejemplo, Dussel (2000) afirma que:

"Decir mundo es enunciar un proyecto temporalmente futuro; es igualmente afirmar un pasado dentro de una espacialidad que por ser humana significa ser centro del mundo, pero dicho mundo puede que sea periférico de otros mundos. Por ello nuestra filosofía de la liberación fijará su atención sobre el pasado del mundo y sobre la espacialidad, para detectar el origen, la arqueología de nuestra dependencia, debilidad, sufrimiento, aparente incapacidad, atraso" (p. 40).

En otra crítica, Quijano (2000) analiza cómo el "eurocentrismo", tan resaltado en el patrimonio mundial, se relaciona también con un modo de producción y control de relaciones intersubjetivas, incluidos el imaginario social, la memoria histórica y la generación de conocimientos. La imposición de un enfoque distorsionado sobre los dominados les obliga a verse con los ojos del dominador, lo cual bloquea y encubre una perspectiva histórica y cultural autónoma.

En coincidencia con Mignolo (2007), los relatos de la modernidad, como este de la conservación del patrimonio mundial bajo cánones de apariencia universal, generan ausencias que crean una herida colonial, un sentimiento de inferioridad impuesto en los seres humanos que no encajan en el modelo predeterminado por las narrativas euroamericanas, razón por la cual se requiere una transformación epistémica, geopolítica, corporal.Y es que, en la actual crisis civilizatoria, es oportuna una transición ecológica y cultural profunda para "sentipensar" con la tierra, para territorializar a las comunidades en un nuevo arte de vivir y crear alternativas verdaderas hacia un patrimonio mundial más entendido como un "pluriverso" (Escobar, 20I4).

En conjunto, con los fundamentos teóricos críticos del patrimonio, la nueva geopolítica y la geopolítica latinoamericana anteriormente expuestos, se analizará cómo se ha manifestado el patrimonio mundial en la región latinoamericana y caribeña. 


\section{Análisis crítico de los territorios de América Latina y el Caribe en la Lista del Patrimonio Mundial}

Un análisis regional del patrimonio mundial debe partir por reconocer que, al interior de la UNESCO, la regionalización misma ha implicado un trazo geopolítico. El desequilibrio en las representaciones regionales y el poco apego geográfico han sido críticas constantes al Comité del Patrimonio Mundial.Actualmente la UNESCO reconoce las regiones de: África,Asia y Pacífico, Estados Árabes, Europa y Norteamérica, así como América Latina y el Caribe. Resalta que Estados Unidos y Canadá, a pesar de estar continental e históricamente unidos con ALyC, forman parte del bloque europeo debido a una controvertida decisión tomada en 1973 por claras razones políticas (Meskell et al., 20I5). Actualmente, el Centro del Patrimonio Mundial (202I) concibe a ALyC, como una región conjunta, la cual subdivide con fines meramente de planeación en tres: México y Centroamérica, el Caribe y Sudamérica.

En el proceso histórico de adhesión a la convención de 1972 por parte de los países de la región, se observa una adopción tardía, además de presentar iniciales reticencias y desconfianza. En aquellos años, ALyC estaba inmersa en los efectos de la inestabilidad política, golpes de estado, guerrillas y militarización por la confrontación ideológica propia de la Guerra Fría; la protección del patrimonio cultural no era una prioridad en esas circunstancias.

Inicialmente permeaba una desconfianza hacia la convención, se temía que pudiera ser un mecanismo de EEUU para incidir en los territorios latinoamericanos dentro de su confrontación con la Unión de Repúblicas Socialistas Soviéticas (URSS). A pesar de esto, según la relación de estados miembro (Centro del Patrimonio Mundial, 202I), los primeros países latinoamericanos que ratificaron la convención a lo largo de la década de los setenta fueron, por orden cronológico, Ecuador, Bolivia, Guyana, Costa Rica, Brasil, Panamá,Argentina, Guatemala, Honduras y Nicaragua. Un impulso que animó a estos primeros países fue la favorable asociación de la UNESCO con el Movimiento de Países No Alineados (MPNA), lo cual permitió que líderes, como Brasil y Argentina, se decantaran por la aprobación del instrumento internacional en 1977 y 1978, respectivamente. EI MPNA congenió con la salvaguarda del patrimonio mundial al compartir los principios de apuesta por la paz, el multilateralismo, la diplomacia como solución de controversias y la no intervención en la soberanía de los países.

Para la década de los ochenta, varios países latinoamericanos mantenían los temores de que la Convención del Patrimonio Mundial fuese una estrategia en contra de la integridad territorial, autonomía en asuntos internos y la libre autodeterminación. Sin embargo, los cuestionamientos sobre el posible uso de la UNESCO como una estrategia estadounidense se disiparon en 1983: este país decidió abandonar la organización argumentando su tendencia a politizar los asuntos tratados, así como su creciente burocracia. En realidad, para los estadounidenses la UNESCO implicaba un alto costo presupuestal y dejó de ser un posible instrumento de contrapropaganda por la creciente vigilancia y contrapeso del MPNA (Waxman, 2017).' Fue así como a lo largo de

\footnotetext{
Cabe mencionar que EEUU regresó a la UNESCO en 2002 (tras diecinueve años de ausencia), su retorno pudo estar vinculado con una ofensiva ideológica contraterrorista por los atentados del $9 / 1$ I. Sin embargo, tan solo unos años después, este país volvió anunciar su retiro de la organización el 31 de diciembre de 2018 . En esta ocasión se alegó que la organización no era imparcial, cuando en 201 I la UNESCO admitió a Palestina como estado miembro y además permitió que, en el 2017, subdelegación inscribiera la ciudad de Hebrón y la mezquita de Ibrahim como patrimonio mundial en peligro, ignorando la oposición de Israel y sus aliados.
} 
la década de los ochenta, ya en el deshielo de la Guerra Fría, numerosos países latinoamericanos se animaron a ratificar la convención. Tales fueron los casos en orden cronológico de Haití, Chile, Cuba, Perú, Colombia, Jamaica, Antigua y Barbuda, México, República Dominicana, San Cristóbal y Nieves, Paraguay, así como Uruguay (Centro del Patrimonio Mundial, 202I).

Para la década de los años noventa e inicios del siglo XXI, los países latinoamericanos restantes firmaron el acuerdo internacional, la mayoría de ellos pequeños estados insulares del Caribe que no habían obtenido totalmente su independencia hasta esas fechas, o bien países que lograron una restructuración después de las guerrillas o inestabilidad política de décadas anteriores. Fueron las circunstancias de Venezuela, Belice, El Salvador, Santa Lucía, Dominica, Surinam, Granada, Barbados, San Vicente y las Granadinas, Trinidad y Tobago, y, Bahamas (Centro del Patrimonio Mundial, 202I). En la actualidad, de los treinta y tres países de ALyC reconocidos por la Organización de las Naciones Unidas, cada uno de estos son parte de la convención. Esto vuelve a la región latinoamericana una de las más comprometidas al respecto, por lo menos en intencionalidad.

Otro punto relevante que debe considerarse sobre el papel del ALyC en el patrimonio mundial es su subrepresentación en el inventario global. Actualmente, en los inicios del año 202I, hay un total de mil ciento cincuenta y tres propiedades en la Lista del Patrimonio Mundial de las cuales ciento cuarenta y seis se ubican en países latinoamericanos y caribeños. Esta región, a pesar de formar parte del segundo continente más grande del planeta, incluye apenas un $12,71 \%$ del enlistado total, estando el resto distribuido en Europa y Norteamérica (47,08\%), Asia y el Pacífico (24,I I\%), África (8.44\%) y los Estados Árabes (7,66\%) (Centro del Patrimonio Mundial, 2021). Hemos mencionado que una de las principales críticas hacia la distribución de las propiedades del patrimonio mundial es su concentración en el territorio europeo, como muestra tenemos que los sitios de Italia, España y Alemania suman conjuntamente ciento cincuenta y seis, esto es diez sitios más que la región total de ALyC.

El país latinoamericano con más propiedades del patrimonio mundial inscritas es México (treinta y cinco propiedades), pero ocupa apenas el séptimo lugar internacional después de Italia (cincuenta y siete propiedades), China (cincuenta y seis propiedades), Alemania (cincuenta propiedades), España (cuarenta y nueve propiedades), Francia (cuarenta y ocho propiedades) e India (cuarenta propiedades) según lo enlista el Centro del Patrimonio Mundial (202I). El caso de México es peculiar ya que es el único en alcanzar esas elevadas cifras, pero no refleja la realidad del resto de su grupo regional. La situación sui géneris mexicana se explica no solo por su tamaño y riqueza cultural sino, entre otros aspectos, por los ejes de su política exterior en favor de la cooperación cultural y el multilateralismo, su tradición diplomática de participación constante y nutrida en la UNESCO, su afinidad con los modelos de conservación adoptados de Francia, así como por sus instituciones de gestión cultural nacionalistas y centralizadas surgidas de su revolución social en los inicios del siglo $\mathrm{XX}$.

Los estados latinoamericanos que históricamente han disputado el liderato de la región (Argentina, Brasil y México) encabezan también los primeros cinco escaños del patrimonio mundial en la región: México (treinta y cinco propiedades), Brasil (veintitrés propiedades), Perú (trece propiedades) y Argentina (once propiedades). El resto de los países latinoamericanos 
concentran menos de diez propiedades registradas habiendo varios, sobre todo los caribeños y centroamericanos, que tienen tan solo un bien enlistado (Antigua y Barbuda, Barbados, Belice, Dominica, República Dominicana, El Salvador, Haití, Jamaica, Paraguay, Santa Lucía, y, San Cristóbal y Nieves). Los únicos países de la zona que, a pesar de haber suscrito la convención, no tienen ninguna propiedad enlistada son Bahamas, Granada, Guyana, San Vicente y las Granadinas, al igual que Trinidad y Tobago (Centro del Patrimonio Mundial, 202I). Una subrepresentación caribeña se perfila evidente.

Sin duda los principales retos que ha enfrentado la región para estar, de forma más equilibrada, en la Lista del Patrimonio Mundial han sido sus deficiencias políticas y económicas estructurales, pues esto le ha impedido cumplir los requisitos procedimentales y participar activamente en los órganos internacionales decisorios. Para que las propiedades naturales y culturales de ALYC reciban la declaratoria de patrimonio mundial hay que convencer al Comité del Patrimonio Mundial y a los organismos técnicos asesores como el Consejo Internacional de Monumentos y Sitios (ICOMOS) y la Unión Internacional para la Conservación de la Naturaleza (UICN). Dentro del Comité del Patrimonio Mundial ha persistido poca equidad en la representación regional dando prioridad a los países de la región europea (Meskell et al., 20I5a), por lo que ALyC no ha figurado.A pesar de que algunos países de la región sí tienen una larga tradición de participación en el comité por varios periodos como Argentina, Brasil, Colombia, Cuba, Perú y México, el resto encuentra dificultades técnicas, diplomáticas o económicas para lograrlo. En el comité vigente, los países elegidos representando a la zona son Brasil, Guatemala y, San Cristóbal y Nieves (Centro del Patrimonio Mundial, 202I).

El Comité del Patrimonio Mundial se reúne en forma anual para inscribir propiedades en la lista ${ }^{2}$, por lo que la disputa entre países por convertirse en sede de esta estratégica reunión es constante. De las cuarenta y tres reuniones que reporta el comité, $A L y C$ ha sido sede solo en cinco ocasiones: Buenos Aires,Argentina ( 1984); Brasilia, Brasil (1988 y 20 I0); Cartagena, Colombia (1993) y Mérida, México (1996).

Cada país es el encargado de detectar y proponer propiedades en su territorio para la inclusión en la Lista del Patrimonio Mundial, para lo cual debe preparar un laborioso y costoso expediente que argumente en forma convincente su valor excepcional. Además, el expediente de candidatura tiene que detallar las características específicas de la propiedad, la regulación jurídica al interior del estado, las medidas de conservación y un, cada vez más riguroso, plan de manejo. Sobra decir que países empobrecidos, como varios de la región latinoamericana y caribeña, están prácticamente imposibilitados para emprender estas dispendiosas iniciativas o para cumplir con todos los requisitos, ajenos a sus políticas culturales y capacidades tecnológicas o de infraestructura.

En breves palabras, para enlistar propiedades en apego a la convención de 1972 se requiere una serie de factores que van desde una tenaz capacidad de negociación diplomática, hasta fuertes instituciones internas, solvencia presupuestal, control territorial, políticas culturales eficaces, compatibilidad entre leyes o capacidad de atracción turística. Los procesos de inscripción de los

2 Por primera vez en toda su historia, la sesión número 44 del Comité del Patrimonio Mundial se canceló el año 2020 debido a la emergencia sanitaria mundial por el coronavirus SARS-CoV-2 y se realizó hasta el mes de julio del 2021. 
sitios latinoamericanos y caribeños están estructuralmente supeditados a intereses nacionales, estrategias y potencialidades de cada uno de los países (sobre todo en forma individual y no tanto por una acción regional o subregional en bloque).

En este proceso de alienación territorial, la adaptación de categorías patrimoniales exógenas ha sido también un claro problema regional. El Centro del Patrimonio Mundial clasifica las propiedades en tres tipos: patrimonio natural, patrimonio cultural y patrimonio mixto. La región de $\mathrm{AlyC}$ ha encontrado dificultad para encajar dentro de estas rígidas subdivisiones. En forma global, con cálculos basados en las cifras oficiales (Centro del Patrimonio Mundial, 202I), la distribución del patrimonio mundial en la región corresponde a $26,6 \%$ de patrimonio natural, $67,8 \%$ de patrimonio cultural y $5,6 \%$ de patrimonio mixto. Visiblemente prevalecen espacios conmemorativos de manifestaciones culturales por encima de los espacios de la naturaleza y los mixtos.

En una lectura más fina, los nombres de las propiedades inscritas por ALyC muestran una adaptación a la evolución de categorías que fueron surgiendo por las críticas hacia la UNESCO, esto buscando garantizar la aceptación del comité para ser enlistados. Las primeras nominaciones referenciaban monumentos, sitios, parques nacionales, áreas naturales, sitios arqueológicos, centros históricos, mientras que las más recientes evocan paisajes culturales, patrimonio moderno, zonas industriales, rutas culturales y complejos sistemas de reservas naturales. En este proceso se muestra claramente el ejercicio de renombrar y adoptar etiquetas que teóricamente se ha explicado en el apartado anterior.

Se confirma que también ALyC afronta un gran desafío para cumplir con los criterios del valor excepcional y la autenticidad; se puede ilustrar esta situación con ejemplos concretos. A principios de 1980, se originaron debates en el Comité del Patrimonio Mundial sobre si las ciudades históricas podían ser incluidas en la definición del patrimonio mundial, se discutía su autenticidad al ser espacios habitados y modificados por el uso cotidiano. Justamente las inscripciones de varios centros urbanos latinoamericanos desataron esas discusiones en los casos de Brasil (Ouro Preto, Ciudad de Olinda y Salvador de Bahía), México (Ciudad de México, Oaxaca y Puebla), Cuba (Vieja Habana), Guatemala (Antigua) y Perú (Cuzco). Después de arduas negociaciones, se concluyó que solo pequeños centros históricos y no grandes metrópolis podrían considerarse como patrimonio mundial (Centro del Patrimonio Mundial, 1994).

En esa misma tesitura, la inscripción de la ciudad de Brasilia fue muy controvertida porque, además de ser un centro urbano, se cuestionaba su edificación reciente en 1956, esto como resultado de un hito en la historia de la planeación urbana moderna.A pesar de algunas reticencias, al final de cuentas se logró su enlistado en 1987 (justamente cuando la ciudad brasileña fue sede la reunión anual del comité). Similar debate ocasionó inscribir zonas de carácter "proto-industrial, artesanal o tradicional" (Pressouyre, 1993, p.28). Se asumía que solo los países desarrollados podrían ser ejemplos de la evolución industrial, por lo que se dudaba que ALyC fuera realmente representativa en este sentido. La solución hallada fue asociar esos lugares con ciudades coloniales, como una especie de sinónimo de industrialización, así pasó en 1987 cuando se registraron bajo esos títulos las Minas de Plata de la Ciudad de Potosí (Bolivia) y, un año más tarde, Guanajuato y sus Minas Adyacentes (México), así como Trinidad y el Valle de los Ingenios (Cuba). 
Uno de los efectos más alienantes ha sido la adopción acrítica de narrativas históricas y selección de eventos del pasado, aspectos reflejados en las propiedades regionales formando parte del patrimonio mundial. Las élites culturales o cuerpos diplomáticos de los países de la zona son los encargados de redactar las justificaciones centrales sobre la valía universal de esos espacios. Intentando garantizar el reconocimiento de la UNESCO, se adoptan y reproducen argumentos dominantes que minimizan o anulan otras versiones de la historia. En dichas justificaciones es posible encontrar la memoria de élite institucionalizada (Nora, 1984), asociada con una previa apropiación nacionalista y la implantación de metanarrativas. Tomaremos un par de ejemplos para evidenciar este proceso.

El patrimonio mixto podría ser la categoría que mejor se adapta a la historia de ALyC, sin embargo hasta ahora solamente ocho propiedades en la región representan esta denominación argumentando la fusión de la naturaleza con culturas precolombinas: Paraty e llha Grande en Brasil; Parque Chiribiquete en Colombia; Machu Picchu, el Parque de Río Abiseo, ambos en Perú; Parque de Tikal en Guatemala; Montes Blue y de John Crow en Jamaica; y,Valle de Tehuacán Puebla así como Calakmul en México (Centro del Patrimonio Mundial, 2020).

Respecto al patrimonio natural mundial puede considerarse que está subrepresentado, sobre todo considerando que en la región se ubican ocho de los doce países megadiversos del planeta. En los argumentos se evocan ecosistemas únicos, hábitats originales, diversidad ambiental, paisajes excepcionales por su belleza, protección de especies endógenas de flora y fauna, exoticidad de paisajes, pureza de entornos y aportes para el desarrollo o evolución de la ciencia.

Hace años que Said (1996) argumentó que los puentes entre la cultura y el imperialismo están justamente mediados por narrativas e imágenes, sobre todo en aquel cruce entre colonizadores y colonizados. Curiosamente, los argumentos de inscripciones de los sitios naturales de ALyC al patrimonio mundial recuerdan las narraciones de viajeros, naturalistas y expedicionarios del s. XV al XIX, quienes forjaron lazos de atracción y dominio entre Europa y el continente americano, con la biodiversidad como un eje de alteridad (Ventura, 2018). Un ejemplo puntual de dicha situación se observa en la inscripción del Santuario de Malpelo en Colombia, cuya ficha oficial descriptiva (Centro del Patrimonio Mundial, 202I, s.p.) argumenta su excepcionalidad porque:

"La isla de Malpelo es, en particular, un santuario para meros gigantes, peces voladores y especies raras de tiburones. Su costa está considerada como uno de los más extraordinarios sitios del mundo para el buceo, debido a la excepcional belleza de sus abruptos acantilados y grutas. Además, sus aguas profundas sirven de refugio a un número considerable de especies pelágicas y grandes depredadores marinos, cuyo comportamiento natural permanece inalterado en este medio ambiente protegido".

La memoria histórica que se perfila en ALyC a través de sus propiedades naturales del patrimonio mundial enfatiza, igualmente, la belleza natural de dos ecosistemas afamados: los Andes 
y el Amazonas. Representando a los Andes se han inscrito el Parque Nacional los Glaciares y el Parque Nacional los Alerces de Argentina, el Parque Sangay de Ecuador y el Parque Huascarán de Perú. Del Amazonas se han inscrito el Parque Iguazú de Argentina, el Parque Noel Kempff Mercado de Bolivia y la Zona de Conservación de la Amazonia Central brasileña.

En ALyC la noción de una naturaleza separada de la cultura es inconcebible para muchos de sus pueblos originarios, de ahí tal vez que esta categoría binaria de patrimonio natural segmentada del patrimonio cultural sea tan anómala y se haya convertido en una de las críticas más agudas, tanto en los teóricos decoloniales como en los movimientos locales de defensa de la tierra, los movimientos medioambientalistas y las reivindicaciones indígenas que observan en estos nombramientos una artificialidad.

Por su parte, las propiedades culturales de la región, elegidas para representar al patrimonio mundial, conmemoran muy genérica y selectivamente el pasado prehispánico. Estos sitios enaltecen en forma evidente la herencia colonial que, por historia regional, es dominantemente española y portuguesa. Asociativamente, la remembranza de testimonios religiosos (particularmente del cristianismo católico) es también una constante. Varios de estos sitios aluden y refuerzan una tradición extractivista y defensiva en torno a antiguos centros de poder, por lo cual centros mineros, zonas productoras de sal, rutas de comercio, haciendas, fábricas tradicionales, murallas, baluartes terrestres o marítimos han sido incluidos en ese inventario mundial.

Tomemos como ejemplo el caso del Caribe, en donde un solo sitio rememora a las primeras tribus caribeñas existentes antes del colonialismo europeo: el Parque Alejandro de Humboldt en Cuba (que además lleva el nombre del afamado expedicionario alemán). Por tanto, la mayoría de los sitios elegidos enaltecen la herencia colonial de los diferentes países europeos que arribaron a la zona, enfatizando fuertemente la infraestructura militar y defensiva. Estos serían los casos de la Antigua Naval Dockyard del país Antigua y Barbuda, el Centro Histórico de Bridgetown y su Guarnición Militar en Barbados, el Castillo de San Pedro de la Roca en Cuba y el Parque de la Fortaleza de Brimstone Hill en San Cristóbal y Nieves. Sobre este último sitio, el argumento presentado sobre su valor excepcional (Centro del Patrimonio Mundial, 202I, s.p.) determina que:
"Proyectada por los británicos y construida por esclavos africanos, la fortaleza de Brimstone Hill se halla en un admirable estado de conservación y constituye un ejemplo notable de la aplicación de los principios de la arquitectura militar de los siglos XVII y XVIII al contexto caribeño.Además, esta fortaleza constituye un testimonio de la expansión colonial europea, la trata de esclavos y el surgimiento de nuevas sociedades en la región del Caribe".

En Centroamérica igualmente hay pocas evocaciones sobre las manifestaciones culturales de los primeros pobladores del continente americano, quienes además son etiquetados con el marcador europeo de precolombinos o prehispánicos.

Una excepción notable sería la conmemoración particular de la civilización maya (con 
los sitios arqueológicos de Tikal, Quiriguá, Copán, Palenque, Chichen Itzá, Uxmal y Calakmul). Sin embargo, la realidad muestra que el riesgo de la "mayanización" (Silverman, 20I I, p. 27) de la memoria histórica es que nutre una visión idolatrada, turística y estereotipada de los antiguos mayas sobre la real marginación y diversidad de los pueblos mayenses de la actualidad.

Si Centroamérica muestra una predilección por los mayas, en Sudamérica se invocan enfáticamente los testimonios de la civilización inca: desde Argentina (Quebrada de Huamahuaca), pasando por Bolivia (Fuerte de Samaipata) y, por supuesto, Perú (Ciudad de Cuzco, Machu Picchu). Inclusive, uno de los pocos sitios transfronterizos del patrimonio de la humanidad de América Latina se ubica justamente en Sudamérica y alude al llamado Sistema Vial Andino Qhapaq Ñan (propuesto conjuntamente por Argentina, Bolivia, Chile, Colombia, Ecuador y Perú). De nueva cuenta, esta predilección por el pasado incaico representa una simplificación que oculta complejos procesos de narrativas exógenas de progreso, idealización exótica, etiquetas turísticas, reapropiaciones nacionalistas, despojo de pobladores locales que hacen del camino de los incas un "señuelo patrimonial” (Argüello, 2019).

A pesar de la innegable impronta de la población negra en $A L y C$, así como de las históricas rebeliones y oposiciones hacia los procesos de conquista y colonización, enfáticamente solo dos propiedades conmemoran la resistencia y participación de los esclavos negros: el patrimonio mixto de Montes Azules y John Crow en Jamaica y el sitio arqueológico Muelle de Valongo en Brasil. Muy pocas conmemoraciones aluden los procesos de independencia que se remiten a casos en México (Centro Histórico de Querétaro) y Haití (el Parque Citadel, Sans Souci, Ramiers).

Las diferencias subregionales se diluyen cuando se enaltece el pasado colonial. Ciudades históricas heredadas de la etapa colonial, invocadas por su arquitectura o infraestructura productiva, antiguos enclaves geopolíticos, fortificaciones defensivas son acríticamente seleccionados. Bajo la lectura de estas narrativas e imágenes se dulcifica el colonialismo, se mira como conciliador e inevitable, como una transición necesaria hacia una especie de refinamiento estético y cultural. Este tipo de propiedades asociadas con la colonia son el grueso la Lista del Patrimonio Mundial en ALyC. Se presentan argumentos de selección enarbolando la estética, arquitectura y riqueza cultural. Sirva de muestra la nominación de Antigua (Centro del Patrimonio Mundial, 202I, s.p.) que enuncia:

"La ciudad de Antigua, sede de la Capitanía General de Guatemala, fue fundada a principios del siglo XVI [...] Construida con arreglo a un trazado en damero inspirado en los principios del Renacimiento italiano,Antigua llegó a poseer en menos de tres siglos un gran número de monumentos soberbios".

Increíblemente ejemplos de extracción masiva de recursos que comenzaron con la articulación periférica de la región a un sistema capitalista extractivo (Escobar, 20l4), se anulan bajo narrativas de "prosperidad" o "esplendor". Una muestra está en el Centro Histórico de Zacatecas en México, cuya inscripción por el Centro del Patrimonio Mundial (202I) arguye que: “...se fundó en 1546, poco después del descubrimiento de un rico filón de plata, y prosperó 
gracias a la explotación de este metal precioso, alcanzando su apogeo en los siglos XVI y XVIl”. Esto se repite en la Ciudad Histórica de Ouro Preto en Brasil (Centro del Patrimonio Mundial, 202 I, s.p.) que dicta:

"Fundada a finales del siglo XVII, la ciudad de Ouro Preto (Oro Negro) fue el punto de convergencia de los buscadores de oro y el centro de la explotación de minas auríferas en el Brasil del siglo XVIII. La ciudad declinó con el agotamiento de sus minas a principios del siglo XIX, pero todavía subsisten muchas iglesias, puentes y fuentes que atestiguan su pasado esplendor".

La herencia del cristianismo católico es otra rememoración vanagloriada por muchas propiedades patrimoniales en todas las subregiones. Numerosos lugares recuerdan con naturalidad la grandeza del patrimonio religioso y, en ocasiones, su fusión con la manufactura indígena en la construcción de estéticos templos e iglesias. Sin mencionar las confrontaciones y la complejidad real que ha representado la presencia de la iglesia católica en el pasado latinoamericano, se aplaude sin dudar los logros de la cristianización, la riqueza artística heredada con diferentes estilos arquitectónicos europeos y los logros de la evangelización.

De la vasta cantidad de propiedades bajo esta línea argumentativa enunciamos solo, como notable ejemplo, la justificación valorativa de las Misiones Jesuíticas de Chiquitos en Bolivia (Centro del Patrimonio Mundial, 202I, s.p.) donde se expresa que:

"Este sitio comprende seis reducciones fundadas por los jesuitas entre 1696 y 1760. La organización de estas poblaciones de indios convertidos al cristianismo se inspiró en las ciudades ideales de los filósofos del siglo XVI. El estilo de las construcciones es fruto de la fusión de la arquitectura católica con las tradiciones locales".

Las únicas excepciones a estas líneas de rememoración ancladas en el periodo colonial, corresponderían a las propiedades del llamado patrimonio moderno (correspondiente al siglo $\mathrm{XX)}$. No obstante, los intentos por resaltar un carácter progresista de la región encuentran pocos exponentes: tres propiedades en México (Hospicio Cabañas, Casa Estudio de Luis Barragán y Campus de Ciudad Universitaria perteneciente a la Universidad Nacional Autónoma de México), tres en Brasil (Río de Janeiro, Ensamble Moderno Pampulha y la Ciudad de Brasilia), uno en Argentina (Obra Arquitectónica de Le Corbusier en la casa del Dr. Curutchet), uno en Chile (Ciudad de Valparaíso), uno en Uruguay (Paisaje Industrial Fray Bentos) y uno en Venezuela (Ciudad Universitaria de Caracas). El patrimonio moderno latinoamericano se pormenoriza. No se conmemoran sitios que evoquen las crudas marcas de los caudillismos, las dictaduras, golpes de estado, revoluciones o guerrillas del siglo $X X$, siendo que son eventos determinantes del pasado regional.

Con esta revisión de las justificaciones para enlistar propiedades del patrimonio mundial en ALyC hemos podido observar el tipo de selección de eventos del pasado y la sacralización de lugares de memoria advirtiendo, con esto, una reproducción de narrativas activadas geopolíticamente. En 
conjunto se reflejan alienaciones territoriales que reproducen discursos históricos nacionalistas y universalistas que rememoran eventos del pasado colonial, pero omitiendo o aminorando otros acontecimientos y actores regionales fuera de estas versiones dominantes de la historia.

\section{Conclusión}

El actual proceso de declaración de un sitio como patrimonio mundial en el marco de la UNESCO y de la convención de 1972 está determinado por los intereses, rivalidades y jerarquías de los estados. El procedimiento que los países deben seguir para enlistar propiedades en la Lista del Patrimonio Mundial favorece una alienación de territorios porque estos deben ser primeramente reconocidos, legitimados y gestionados por un control nacional para, posteriormente, adoptar forzadamente tipologías, categorías y cánones valorativos externos en nombre de una abstracta idea de propiedad de la humanidad. Esta asimilación dentro de metanarrativas diluye o anula otras formas locales de conectarse con el territorio o de generar memorias históricas, puesto que en esta convención prevalece un núcleo estatista y con ello el control territorial geopolítico por sobre otros intereses.

Por lo menos, esta situación se observa en el análisis crítico de las propiedades del patrimonio mundial en ALYC donde prevalece una subrepresentación de la región frente a otras zonas del planeta como Europa y Norteamérica. El margen de acción de América Latina y el Caribe es menor por sus estructurales deficiencias presupuestales, las distintas capacidades nacionales de los países, las desiguales trayectorias gubernamentales, así como la disparidad de capacidades técnicas en torno al patrimonio. Este contexto favorece la alienación territorial a través de la adopción acrítica de narrativas históricas y de categorías valorativas exógenas.

Estos discursos dominantes conmemorados por las propiedades del patrimonio mundial en ALyC, separan artificialmente el patrimonio natural del cultural, demeritan el pasado de los pueblos originarios para enaltecer la herencia colonial y los testimonios materiales del cristianismo católico, depreciando la relevancia de otros eventos históricos contemporáneos y, con esto, otras territorialidades.

Posiblemente, esta situación se replique en otras regiones del mundo e incluso al interior de Europa misma, donde pueden emerger una especie de patrimonios periféricos al margen de las vías institucionales de reconocimiento. En el uso cotidiano del espacio, la declaración de una propiedad como patrimonio mundial suele vincularse más con proyectos turísticos, disputas por la propiedad de la tierra, fenómenos de gentrificación urbana, restricciones y prohibiciones de uso del espacio. Estos nombramientos universalizan, pero también segregan y reproducen jerarquías sociales y territoriales.

Con los resultados del estudio se observa que no basta con reiterar la ya muy conocida crítica del dominio de Occidente en el patrimonio mundial y en la región de ALyC, sino entender sus implicaciones y mecanismos más específicos, evidenciando que en muchos casos hay una autoalienación por parte de las élites culturales latinoamericanas o proyectos nacionalistas. La reproducción acrítica de las narraciones históricas hegemónicas es una parte crucial del problema, 
la necesidad de un cuidadoso revisionismo histórico regional es necesario, más en un actual contexto donde comienzan a darse señales de una radicalización con posturas iconoclastas (como las destrucciones y desmantelamientos de estatuas asociadas con conquistadores).

Por si fuera poco, el dominio occidental en el patrimonio mundial se desvanece frente a nuevas potencias emergentes en la región asiática ¿Cómo entenderá ALyC su posición periférica frente a estos nuevos cambios? El problema central está en visibilizar la riqueza de memorias históricas y formas de construir el patrimonio que han quedado relegadas de esos discursos oficiales y son valoradas como exoticidades en las narrativas nacionales.

Revaluar desde la geopolítica crítica al patrimonio mundial es una propuesta teórica para recentrar al territorio como un eje clave en esta dinámica. No se trata solamente de reconocer sociedades culturalmente diversas, sino de incluir otras formas de generar memorias y relaciones espaciales.

\section{Referencias}

Adell, N., Bendix, R., Bortolotto, C. y Tauschek, M. (2015). Between Imagined Communities of Practice: Participation, Territory and the Making of Heritage. University Press.

Agnew, J. (1993). Representing space: Space, scale and culture in social science. En Duncan J. y, Ley,D. (Eds). Place/ Culture/Representation (pp. 25I-27I). Routledge.

Argüello, P. M. (Ed.) (20/9). El señuelo patrimonial. Pensamientos post-arqueológicos en el camino de los incas: Cristóbal Gnecco. Xpress Estudio Gráfico y Digital S.A.S.- Xpress Kimpres.

Byrne, D. (1991).Western hegemony in archaeological heritage management. History and Anthropology, 5 (2), 269-273.

Centro del Patrimonio Mundial (1994). Expert Meeting on the 'Global Strategy' and thematic studies for a representative World Heritage List. http://whc.unesco.org/archive/ 1994/whc-94-conf003-infl 3e.pdf

Centro del Patrimonio Mundial (202I). World Heritage List. https://whc.unesco.org/en/list/

Choay, F. (1992). Alegoría del patrimonio: monumento y monumento histórico. Arquitectura Viva, (33), 15-2I.

Di Giovine, M.A. (2009). The heritage-scape: UNESCO, world heritage, and tourism. Lexington Books.

Di Giovine, M.A. (20I7). The Heritage-scape: Origins, Theoretical Interventions, and Critical Reception of a Model for Understanding UNESCO's World Heritage Program. Via Tourism Review, (I3), s.p.

Dussel, E. (2000). Filosofia de la Cultural y la liberación. CLACSO.

Escobar, A. (2014). Sentipensar con la tierra. Nuevas lecturas sobre desarrollo, territorio y diferencia. UNAULA.

Graham, B., Ashworth, G. J.y Tunbridge, J. E. (2000). A geography of heritage: power, culture and economy. Arnold.

Harvey, D. (200l). Heritage Pasts and Heritage Presents: temporality, meaning and the scope of heritage studies. International Journal of Heritage Studies, 7 (4), 319-338.

Harrison, R. (2012). Heritage: Critical approaches. Routledge.

Hubbard, P.y Kitchin, R. (Eds.) (20II). Key Thinkers on Space and Place. SAGE.

Iriye, A. (1997). Cultural Internationalism and World Order.The Johns Hopkins University Press.

Jokilehto, J. (2005). The World Heritage List. Filling the Gaps an Action Plan for the Future. UNESCO.

Lowenthal, D. (1998). El Pasado es un país extraño.Akal.

Lowenthal, D. (2005). Natural and cultural heritage. International Journal of Heritage Studies, I I (I), 8 I-92.

Meskell, L; Liuzza, C; Bertacchini, E. y Saccone, D. (20I5a). Multilateralism and UNESCO World Heritage: decisionmaking, States Parties and political processes. International Journal of Heritage Studies, 2I (5), 423-440.

Meskell, L.; Lynn, M.; Liuzza, C. y Brown, N. (20I5b). World Heritage Regionalism: UNESCO from Europe to Asia. International Journalof Cultural Property, 22(4), 437-470.

Mignolo,W. (2007). La idea de América Latina. La herida colonial y la opción decolonial. Gedisa.

Nora, P. (1984). Les lieux de memoire. Gallimard, tomo I.

Ó Tuathail, G. (1996). Critical Geopolitics:The Politics of Writing Global Space. University of Minnesota Press.

Ó Tuathail, G. (1998). Imperialist Geopolitics. En Ó Tuathail, G., Dalby, S. y Routledge, P. (Eds.). The Geopolitics Reader (pp. 15-27). Routledge.

Ó Tuathail, G. y Dalby, S. (2002). Introduction: Rethinking Geopolitics. Towards critical geopolitics. En Ó Tuathail, G. y Dalby, S. (Eds.). Rethinking Geopolitics (Pp. I-I5). Routledge.

Piazzini Suárez, C. E. y Montoya Arango,V. (Eds.) (2008). Geopoliticas: espacios de poder y poder de los espacios. Editorial La Carretera Social.

Pressouyre, L. (1993). La Convention du Patrimoine Mundial vingt ans après. UNESCO. 
Quijano,A. (2000). Colonialidad del poder, eurocentrismo y América Latina. En Lander, E. (Coomp.). La colonialidad del saber: eurocentrismo y ciencias sociales. Perspectivas latinoamericanas. CLACSO.

Rao, K. (20I0).A new paradigm for the identification, nomination and inscription of properties on the World Heritage List. International Journal of Heritage Studies, 16 (3), 6 I - I72.

Riegel,A. (2008). El culto moderno a los monumentos: caracteres y origen. Antonio Machado.

Said, E. (1996). Cultura e imperialismo.Anagrama.

Silverman, H. (20I I). Contested Cultural Heritage. Religion, Nationalism, Erasure, and Exclusion in a Global World. Springer.

Smith, L. (2006). Uses of Heritage. Routledge.

UNESCO (1972). Convención sobre la Protección del Patrimonio Mundial Cultural y Natural, París Francia, 23 de noviembre de 1972. https://whc.unesco.org/archive/convention-es.pdf

UNESCO. (1997). Nuestra Diversidad Creativa. Informe de la Comisión Mundial de Cultura y Desarrollo. Fundación Santamaría. Ediciones UNESCO.

UNESCO (2019). Sobre la UNESCO.

Ventura, A. (0I.09.2018). Viajeros y naturalistas (s. XV-XIX, Europa-América) o cómo viajar sin precauciones por un tema torrentoso. Journals Open Edition.

Waxman, O.B. ( I 2.I0.20I7). The U.S. Has Left UNESCO Before. Here's Why. Time

Wiktor-Mach, D. (2019). Cultural heritage and development: UNESCO's new paradigm in a changing geopolitical context. Third World Quarterly, 40 (9), I593-1612 


\section{RELACIONES INTERNACIONALES}

Revista académica cuatrimestral de publicación electrónica Grupo de Estudios de Relaciones Internacionales (GERI)

Universidad Autónoma de Madrid, España

https://revistas.uam.es/relacionesinternacionales

ISSN 1699 - 3950

f facebook.com/RelacionesInternacionales

3. twitter.com/RRInternacional

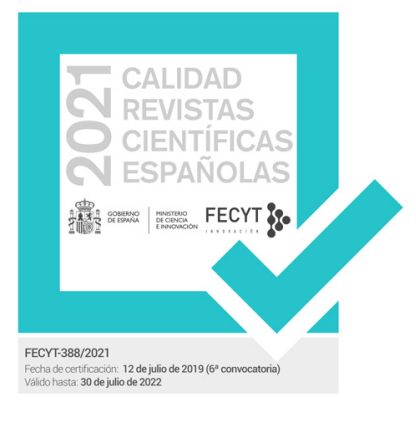

